\title{
Coulisses
}

Revue de théâtre

Les didascalies

\section{Hommage à Harold Pinter}

1930-2008

\section{David Ball}

\section{CpenEdition}

\section{Journals}

Édition électronique

URL : https://journals.openedition.org/coulisses/1465

DOI : $10.4000 /$ coulisses. 1465

ISSN : 2546-9460

Éditeur

Presses universitaires de Franche-Comté

\section{Édition imprimée}

Date de publication : 31 décembre 2009

Pagination : 147-149

ISBN : 978-2-84867-270-0

ISSN : $1150-594 \mathrm{X}$

\section{Référence électronique}

David Ball, «Hommage à Harold Pinter », Coulisses [En ligne], 39 | Automne 2009, mis en ligne le 30 novembre 2016, consulté le 29 décembre 2022. URL : http://journals.openedition.org/coulisses/1465 ; DOI : https://doi.org/10.4000/coulisses.1465

Ce document a été généré automatiquement le 29 décembre 2022.

Tous droits réservés 


\title{
Hommage à Harold Pinter
}

1930-2008

\author{
David Ball
}

Une conversation banale, des plus ordinaires, à propos d'une paire de ciseaux ou de chaussures, par exemple, une conversation d'un rythme, d'une vraisemblance, presque hallucinants, tellement la précision dépasse tout ce que nous restituerait un magnétophone. Et puis, lentement, en partie à cause justement de cette vraisemblance plus vraie que nature, un trouble, une inquiétude, commencent à s'installer chez nous, les spectateurs. Cette situation, ces gens-là, ne sont sûrement pas si ordinaires que ça! Et nous cherchons, d'abord de manière un peu vague et désorientée, la source de nos doutes, de nos soupçons, et puis, de plus en plus précisément, nous la trouvons dans la menace. Soit quelqu'un ou quelque chose les menace de l'extérieur, soit il y a une menace entre eux : l'un d'eux, par exemple, menace sournoisement les autres.

2 Cette idée de menace devient, cependant, si envahissante dans les pièces de Pinter qu'elle risque de perdre à la fin sa force, sa pertinence. Si la menace est comme ça, partout, universelle, inévitable, elle risque de perdre ses contours moraux et psychologiques, pour devenir quelque chose qui nous entoure comme un climat, une température, un mauvais temps. Une autre question se pose. Les rôles de ceux qui menacent et de ceux qui sont menacés, sont-ils fixes, donnés dès le départ, ou plutôt interchangeables? Dans sa pièce la plus célèbre, Le Gardien, le chemineau, Davies, a peur du jeune homme, Mick, mais essaie de dominer la victime des traitements psychiatriques d'électrochocs, Aston. Aston, pourtant, enfin provoqué par l'agressivité bête et méchante de Davies, l'oblige à partir de la maison où, autrement, il aurait pu trouver refuge.

3 L'ambiance de menace et de violence psychologiques dans les premières pièces de Pinter cède la place à une violence physique, organisée, dans les pièces politiques de la suite de sa carrière. Dans ces pièces, il dénonce les pratiques de répression, de persécution et de torture infligées aux minorités et aux dissidents par des gouvernements militaires ou autoritaires alliés aux États Unis. Sa pièce courte et puissante, Langue de la montagne (Mountain Language), en est typique, inspirée par l'interdiction de leur langue infligée aux Kurdes par l'état turc. Parfois, pourtant, une 
mauvaise joie à pouvoir dénoncer les Américains fait tomber Pinter dans une violence, verbale, qui fait penser davantage à une complicité inavouable qu'à une vraie opposition fondée sur d'autres valeurs. Son discours d'acceptation du prix Nobel à Stockholm est un réquisitoire implacable mais bien argumenté contre la politique étrangère des États Unis depuis des décennies, mais ses discours et autres interventions contre l'invasion anglo-américain de l'Iraq furent souvent d'un excès qui gênait ses amis, tout comme la plupart des poèmes politiques de ses dernières années. Son sens de l'humour et de la litote semble l'avoir déserté vers la fin de sa vie.

4 L'influence sur ses débuts de la comédie absurde et nihiliste de Beckett et d'Ionesco est évidente et bien connue, mais d'un autre côté, il ne faut pas négliger l'influence possible d'éléments de la culture populaire anglaise beaucoup moins connus en France : les traditions du music hall, le parler populaire du Londres des origines de l'auteur (le bagou cockney) et les émissions radiophoniques des années quarante et cinquante, telles qu'ITMA, The Goon Show, Hancock's Half Hour et Beyond Our Ken, qui se spécialisaient, avec énormément de succès, dans un humour typiquement britannique, inventif, farfelu et impertinent. Cette influence fut sans doute indirecte et même parfois négative, dans le sens que ses aspects jugés trop faciles auraient poussé des auteurs ambitieux et innovateurs, tels que Pinter et les autres dramaturges du renouveau du théâtre britannique de la fin des années cinquante, à quelque chose de plus sérieux et de plus contestataire. Un élément de l'originalité de ces auteurs fut de présenter de manière sympathique et convaincante des aspects de la vie des gens modestes, des ouvriers et des marginaux.

5 C'est probablement dans Le Retour (The Homecoming) de 1965 que l'on trouve le plus d'éléments comiques typiques des émissions radiophoniques, éléments de contradiction et de coq-à-l'âne, d'insultes inventives et de parodie (du discours philosophique, par exemple). La pièce est pleine de menace; tous les personnages essaient d'être menaçants à un moment donné mais, pour la plupart, de façon peu convaincante. Le monde masculin des premières pièces de Pinter est typique, lui aussi, des émissions radiophoniques (The Goon Show, par exemple, trois voix masculines, tout comme Le Gardien). Des six personnages du Retour, cinq sont des hommes : le vieux père et ses trois fils et le frère du père, et la pièce se termine sur une misogynie désinvolte : la femme du fils qui vient de rentrer à la maison semble accepter sans état d'âme de se prostituer pour contribuer aux finances familiales.

6 Au milieu de sa carrière, dans les années 1970, Pinter écrivit plusieurs pièces, peut-être ses chefs-d'œuvre, consacrées au couple et au mariage dans un contexte de vie bourgeoise et cultivée, la vie de succès de Pinter lui-même, mais consacrées surtout aux ravages de l'infidélité, ravages d'autant plus dévastateurs qu'ils sont cachés, devinés, toujours incertains. C'est dans les relations les plus intimes, n'est-ce pas, que l'on a le plus d'intérêt, de tentation et d'occasion, de mentir. Dans sa pièce de 1971, C'était hier (Old Times), trois personnages d'environ quarante ans parlent de façon décousue de leur passé : un homme et deux femmes, l'une son épouse et l'autre la meilleure amie de son épouse à l'époque où les deux jeunes femmes vivaient ensemble et où l'homme commençait à faire leur connaissance. Ils parlent du passé, des cinémas, des théâtres et des cafés de Londres, mais ils parlent aussi du présent : du boulot du mari qui l'oblige à voyager et de la maison en Sicile de la meilleure amie. Mais leur façon vague de parler de tout cela nous fait douter de sa réalité, et nous n'aurons pas d'idées plus claires à propos de leurs relations intimes. Il y eut évidemment une histoire quelconque entre 
l'homme et la meilleure amie, mais fut-ce une histoire de rivalité entre les deux femmes ou de mensonges de la part de l'homme?

7 Trahison (Betrayal, 1978), par contre, évite apparemment toute ambiguïté, toute incertitude. D'un réalisme implacable mais parfaitement maîtrisé, la pièce présente, en ordre non chronologique, les étapes d'une relation adultère où l'amant est le meilleur ami du mari trahi. On commence à la fin pour terminer au début, quand l'amant, éméché, fait sa déclaration d'amour lyrique à la femme de son ami. Plus de menace, nous sommes ici entre gens civilisés. Les relations, les mariages, se font et se défont, la vie est ainsi, et elle continue. Plus stable que l'amour ou l'amitié, la complicité du travail unit les deux hommes, l'un agent littéraire, l'autre éditeur. Malgré tout, pourtant, l'ambiguïté refait surface. À nous de décider, de juger, si de tels gens, de tels milieux, représentent quelque chose d'admirable de sophistication et de savoir-vivre ou, au contraire, de lâche, de frivole et de malhonnête, ou peut-être les deux à la fois : les contradictions de ceux qui essaient de faire rimer plaisir et sincérité. La transparence de la pièce est peut-être finalement son aspect le plus trompeur : même ici, où tout est clair, tout est admis, Pinter reste le maître de l'indirect et du non-dit. 